\title{
Infective endocarditis on transcatheter aortic prosthesis: Are there differences with endocarditis on surgically implanted aortic bioprosthesis?
}

\author{
Consuelo Fernández-Avilés ${ }^{1}$, Juan C. Castillo ${ }^{1,2}$, Gloria Heredia ${ }^{1}$, \\ Adriana Resúa ${ }^{1}$, Rafael González, Manuel Pan ${ }^{1,2}$, Manuel Anguita ${ }^{1,2}$ \\ ${ }^{1}$ Department of Cardiology, University Hospital Reina Sofía, Córdoba, Spain \\ ${ }^{2}$ Biomedical Investigation Maimónides Institute (IMIBIC), University of Córdoba, Córdoba, Spain
}

Transcatheter aortic valve implantation (TAVI) has been a major advance in the treatment of aortic stenosis in elderly patients or those at very high surgical risk, and its indication has been extended to cases of high or even intermediate risk. For this reason, its use has increased notably in the past years [1]. One of the problems associated with TAVI is bioprosthesis infection [2]. The development of infective endocarditis (IE) on TAVI (IETAVI) is a serious complication, with the added problem that in many cases open-heart surgery is necessary to manage it. In patients at high baseline surgical risk, surgery may be contraindicated, or, in any case, the presence of the supporting stent makes the surgical procedure more complex. Some studies have analyzed the incidence of IETAVI, both in Spain [2, 3] and in other countries [4-6]. They all agree on an annual incidence of approximately 1.4-1.6\% and high mortality, ranging from $41.8 \%$ in the Swedish registry of Bjursten et al. [6] to $47.2 \%$ in the Spanish multicenter study by Amat-Santos et al. [3]. They also agree with regard to a high mean age of around 80 years, greater comorbidity (higher incidence of renal failure, previous cancer, higher Charlson index, etc.), and the finding of enterococci, Staphylococcus aureus and coagulase-negative staphylococci as the most frequent microorganisms involved [2-6].

An aspect that has not been well studied yet is the possible difference between IETAVI and IE on surgical aortic valve replacement (IESAVR). Three multicenter registries carried out in different countries (USA, France and Sweden) [4-6] found a similar incidence of IE in both groups, but there is a lack of studies that had compared clinical features, treatment and mortality between these two types of IE. Only 1 French study, using an administrative database, has compared mortality between IETAVI and IESAVR, but without differentiating between biological and mechanical prostheses [5], finding no differences between them. Therefore, given the scarcity of data on this subject, the objective herein, was to evaluate the incidence and characteristics of IE on TAVI, as well as its comparison with biological IESAVR in our hospital, a center of reference for cardiac surgery and invasive cardiology in Spain. For this purpose, two cohorts of patients were analyzed, including all cases of TAVI $(n=520)$ and biological SAVR $(\mathrm{n}=652)$ consecutively implanted in our center between 2012 and 2020, and the incidence of IE is compared in both cohorts, their clinical characteristics, treatment and early in-hospital mortality. Non-parametric tests were used for comparisons (the Pearson exact test for dichotomous variables and the Mann-Whitney test for continuous variables). Continuous variables were expressed as median (interquartile range).

The incidence of IE in the TAVI group $(n=9)$ and in the SAVR group $(\mathrm{n}=11)$ was similar $(1.56 \%$ in the TAVI group and $1.68 \%$ in the surgical group). Age showed a trend to be higher in the IETAVI group: $81(78-82)$ vs. $72(70-79)$ years $(\mathrm{p}=0.18)$.

Address for correspondence: Dr. Manuel Anguita, Menéndez Pidal Av, 1. 14004 Córdoba, Spain, tel/fax: 669635412, e-mail: manuelanguita@secardiologia.es

Received: 27.09.2021 Accepted: 28.10.2021 Early publication date: 15.11.2021

This article is available in open access under Creative Common Attribution-Non-Commercial-No Derivatives 4.0 International (CC BY-NC-ND 4.0) license, allowing to download articles and share them with others as long as they credit the authors and the publisher, but without permission to change them in any way or use them commercially. 
Table 1. Characteristics, treatment and early mortality of infective endocarditis in the overall series and in the two cohorts of patients.

\begin{tabular}{|c|c|c|c|c|}
\hline & $\begin{array}{l}\text { Overall series } \\
(n=20)\end{array}$ & $\begin{array}{l}\text { IETAVI } \\
(n=9)\end{array}$ & $\begin{array}{l}\text { IESAVR } \\
(\mathrm{n}=11)\end{array}$ & $\mathbf{P}$ \\
\hline Age [years]* & $78(72-81)$ & $81(78-82)$ & $72(70-79)$ & 0.17 \\
\hline Female gender & $6(30 \%)$ & $4(44.4 \%)$ & $2(18.2 \%)$ & 0.33 \\
\hline Early infective endocarditis & $10(55 \%)$ & $6(75 \%)$ & $5(45.5 \%)$ & 0.18 \\
\hline Causal microorganism: & & & & 0.65 \\
\hline Staphylococcus aureus & $1(5 \%)$ & $1(11.1 \%)$ & $0(0 \%)$ & \\
\hline Coagulase-negative Staphylococcus & $6(30 \%)$ & $3(33.3 \%)$ & $3(27.3 \%)$ & \\
\hline Enterococcus & $7(35 \%)$ & $2(22.2 \%)$ & $5(45.5 \%)$ & \\
\hline Streptococcus viridans & $3(15 \%)$ & $1(22.2 \%)$ & $2(18.2 \%)$ & \\
\hline Not identified & $3(15 \%)$ & $2(22.2 \%)$ & $1(9.1 \%)$ & \\
\hline \multicolumn{5}{|l|}{ Comorbidity and frailty indexes: } \\
\hline Charlson index ${ }^{*}$ & $4(2-7)$ & $6(4-7)$ & $3(2-5)$ & 0.04 \\
\hline Frail index* & $3(2-4)$ & $3(3-4)$ & $2(2-3)$ & 0.28 \\
\hline \multicolumn{5}{|l|}{ Complications: } \\
\hline Any severe complication & $19(95 \%)$ & $9(100 \%)$ & $10(90.9 \%)$ & 1 \\
\hline Heart failure & $14(70 \%)$ & $6(66.6 \%)$ & $8(72.7 \%)$ & 1 \\
\hline Renal failure & $7(35 \%)$ & $4(44.4 \%)$ & $3(27.3 \%)$ & 0.64 \\
\hline Persistent infection & $13(65 \%)$ & $6(66.6 \%)$ & $7(63.6 \%)$ & 1 \\
\hline Prosthetic dysfunction & $9(45 \%)$ & $3(33.3 \%)$ & $6(54.5 \%)$ & 0.64 \\
\hline Surgical indication: & $13(65 \%)$ & $5(55.5 \%)$ & $8(72.7 \%)$ & 0.64 \\
\hline Operated & $8(62.5 \%)$ & $2(40 \%)$ & $6(75 \%)$ & 0.23 \\
\hline Not operated & $5(38.5 \%)$ & $3(60 \%)$ & $2(25 \%)$ & \\
\hline Type of surgery (on operated cases): & & & & 0.37 \\
\hline Emergent/urgent & $3(37.5 \%)$ & $1(50 \%)$ & $2(33.3 \%)$ & \\
\hline Elective & $5(62.5 \%)$ & $1(50 \%)$ & $4(66.6 \%)$ & \\
\hline In-hospital death & $8(40 \%)$ & $4(44.4 \%)$ & $4(36.4 \%)$ & 1 \\
\hline
\end{tabular}

* Median (interquartile range); IETAVI — infective endocarditis on transaortic valve implantation; IESAVR — infective endocarditis on surgical aortic valve replacement

Frailty, measured by the Frail scale, was similar in both groups: $3(3-4)$ vs. $2(2-3)(\mathrm{p}=0.28)$. Comorbidity, measured by the Charlson index, was significantly higher in the EITAVI group: $6(4-7)$ vs. $3(2-5)(\mathrm{p}=0.04)$. There was a slight predominance of women and of early prosthetic IE in the TAVI group (Table 1). There were no differences between the two groups regarding causal microorganisms (Table 1), being the most frequent coagulase-negative staphylococc $i$ in IETAVI, $37.8 \%$ of the total, and enterococc $i$ in IESAVR, 45.5\% ( $\mathrm{p}=0.65)$. The incidence of severe complications was very high, although similar in both groups (TAVI 88.9\%, SAVR 90.9\%), as was the incidence of the different specific complications, as shown in Table 1. Regarding treatment, there was an indication for surgery, in accordance with the clinical practice guidelines of the European Society of Cardiology, in the same proportion of patients: $62.5 \%$ of the IETAVI group and $72.7 \%$ of the IESAVR group $(\mathrm{p}=0.64)$. However, 5 of the 13 patients $(38.5 \%)$ with an indication for surgery did not undergo surgery due to contraindications or very high surgical risk, and this proportion of patients who did not undergo surgery was numerically higher in the IETAVI group, $60 \%$ vs. $25 \%$ of the IESAVRs $(\mathrm{p}=0.234)$. In operated cases, the proportion of emergent/ /urgent and elective indications was similar in both groups (Table 1). Early in-hospital mortality within the active phase of the disease was high (40\% in the overall series), but was similar in both groups (44.4\% in IETAVI and $36.4 \%$ in IESAVR; Table 1). All deaths were related to endocarditis, except 1 of the 4 in the TAVI group, that was due to pneumonia. 
From the data in the present series, with the limitation of a small sample size, inherent to the low frequency of this type of IE and the single-center nature of the study, it can be concluded that the incidence of IE on TAVI is infrequent and similar to that of surgical bioprosthetic IE, and that, despite a worse risk profile (older age, comorbidity, earlier prosthetic IE, and less surgery performed in indicated cases), the incidence of serious complications and their mortality are similar. This reinforces using TAVI as an aortic valve substitution therapy in elderly or high-risk patients.

\section{Conflict of interest: None declared}

\section{References}

1. Leon MB, Smith CR, Mack MJ. Transcatheter or Surgical AorticValve Replacement in Intermediate-Risk Patients. N Eng J Med. 2016; 374(17): 1609-1620, doi: 10.1056/NEJMoa1514616, indexed in Pubmed: 27040324.
2. Martínez-Sellés M, Bouza E, Díez-Villanueva P, et al. GAMES study group. Incidence and clinical impact of infective endocarditis after transcatheter aortic valve implantation. EuroIntervention. 2016; 11(10): 1180-1187, doi: 10.4244/EIJY15M02_05, indexed in Pubmed: 25671426.

3. Amat-Santos IJ, Messika-Zeitoun D, Eltchaninoff H, et al. Infective endocarditis after transcatheter aortic valve implantation: results from a large multicenter registry. Circulation. 2015; 131(18): 1566-1574, doi: 10.1161/CIRCULATIONAHA.114.014089, indexed in Pubmed: 25753535.

4. Butt JH, Ihlemann N, De Backer O, et al. Long-Term risk of infective endocarditis after transcatheter aortic valve replacement. J Am Coll Cardiol. 2019; 73(13): 1646-1655, doi: 10.1016/j. jacc.2018.12.078, indexed in Pubmed: 30947917.

5. Fauchier L, Bisson A, Herbert J, et al. Incidence and outcomes of infective endocarditis after transcatheter aortic valve implantation versus surgical aortic valve replacement. Clin Microbiol Infect. 2020; 26(10): 1368-1374, doi: 10.1016/j.cmi.2020.01.036, indexed in Pubmed: 32036047.

6. Bjursten H, Rasmussen M, Nozohoor S, et al. Infective endocarditis after transcatheter aortic valve implantation: a nationwide study. Eur Heart J. 2019; 40(39): 3263-3269, doi: 10.1093/eurheartj/ehz588, indexed in Pubmed: 31433472. 